\title{
Ergen Olguda Anevrizma Kanamasının Embolizasyon Yöntemi ile Başarılı Bir Şekilde Tedavisi
}

\author{
Successful Treatment of an Intracranial Aneurysm by the Embolization Method in an \\ Adolescent Patient
}

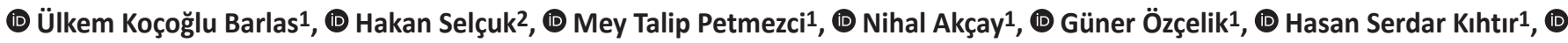 \\ Esra Şevketoğlu1
}

1Sağlık Bilimleri Üniversitesi, Bakırköy Dr. Sadi Konuk Eğitim ve Araştırma Hastanesi, Çocuk Yoğun Bakım Kliniği, Istanbul, Türkiye

2Sağlık Bilimleri Üniversitesi, Bakırköy Dr. Sadi Konuk Eğitim ve Araştırma Hastanesi, Girişimsel Nöroradyoloji Kliniği, İstanbul, Türkiye

\section{Öz}

Intrakraniyal anevrizmalar çocukluk çağında çok az sıklıkta görülmektedir. Klinikte özgül olmayan şikayetlerle karşımıza gelebilecekleri gibi travma tarafından tetiklenip subaraknoid kanama şeklinde de karşımıza çıkabilirler. Tedavilerinde günümüzde endovasküler tedavi seçeneği daha ön plana çıkmaktadır. Bu yazıda kafa travması nedeniyle servisimize yatırdığımız fakat takibinde anevrizma kanaması saptadığımız bir olguyu sunmayı amaçladık. On dört yaşında erkek hasta babasının işyerinde sandalyeden düşmesi sonrasında entübe şekilde acil servisimize başvurdu. Çekilen beyin bilgisayarlı tomografi ve beyin anjiyografisi sonrası kafa travması ön tanısıyla servisimize yatırıldı. Mevcut olan beyin ödemi nedeniyle tedavisi uygulanan hasta yatışının yedinci günü ekstübe edildi. Incelenen görüntülemelerinde anevrizma kanaması olabileceği düşüncesiyle hastaya dijital subtraksiyon anjiyografisi çekildi ve sağ posterior inferior serebral arterde anevrizma odağı saptandı. Aynı seansta koilleme yöntemiyle anevrizma kesesi doldurulan hasta, kontrol bilgisayarlı tomografisinde beyin ödemi ve yeni kanama odağı olmaması nedeniyle yatışının 20. gününde taburcu edildi. Intrakraniyal anevrizma tedavi ve takip seçenekleriyle ilgili literatürü gözden geçirdiğimiz bu olguyu sizlere de sunmayı uygun bulduk.

Anahtar Kelimeler: Anevrizma, embolizasyon, koil, subaraknoid kanama

\section{Abstract}

Intracranial aneurysms are very rarely encountered during childhood. In the clinics, they may be revealed after non-specific complaints or they may be observed as subarachnoid hemorrhage triggered by trauma. Today, endovascular treatment option is more prominent for their management. In this study, we aimed to present a case that we hospitalized in our service due to head trauma and consequently detected a ruptured aneurysm. A fourteen-year-old male patient was admitted to our emergency room as intubated after falling from a chair in his father's workplace. After the brain computerized tomography and brain angiography, he was hospitalized with a pre-diagnosis of head trauma. The patient, who was treated for the existing brain edema, was extubated on the seventh day of hospitalization. The patient underwent digital subtraction angiography with the thought of presence of ruptured aneurysm in the images examined and a focus of aneurysm was detected in the right posterior inferior cerebral artery. The patient whose aneurysm sac was filled with gas by coil embolization technique during the same session was discharged on the $20^{\text {th }}$ day of his hospitalization without brain edema and new focus of bleeding during his control computed tomography. We wanted to share this case study, in which we reviewed the literature about intracranial aneurysm treatment and follow-up options.

Keywords: Aneurysm, embolization, coil, subarachnoid hemorrhage

\section{Giriş}

Subaraknoid kanama (SAK); sıklıkla anevrizma rüptürü sonrasında ortaya çıkan, kanın beyin omurilik sıvısına geçme durumudur. ${ }^{1}$ Toplumda intrakraniyal anevrizma (IA) görülme sıklığı 6-8/100.000 kişi olmakla birlikte, bu sayının \%0,6-6,8'ini çocukluk yaş grubu oluşturur. ${ }^{2,3}$ Tedavisinde

Yazışma Adresi/Address for Correspondence: Ülkem Koçoğlu Barlas, Sağlık Bilimleri Üniversitesi, Bakırköy Dr. Sadi Konuk Eğitim ve Araştırma Hastanesi,

Çocuk Yoğun Bakım Kliniği, İstanbul, Türkiye

E-posta: ulkemkocoglu@yahoo.com ORCID ID: orcid.org/000-0001-7445-5858

Geliş Tarihi/Received: 29.04.2020 Kabul Tarihi/Accepted: 22.07.2020 
endovasküler ve cerrahi yöntemler seçilebilmekle beraber, çalısmalar endovasküler tedavinin daha güvenilir olduğunu göstermiştir. ${ }^{4}$ Biz de bu yazıda posterior inferior serebral arter (PiCA) anevrizma kanamasına bağlı SAK'si olan 14 yaşında erkek olguda başarılı bir endovasküler tedavi örneğini sunmayı amaçladık.

\section{Olgu Sunumu}

On dört yaşında erkek hasta babasının işyerinde sandalyeden düşme şikayeti ile acil servisimize başvurdu. Öyküsünde hastanın düşme sırasında önce ensesini diğer sandalyenin metal kenarına çarptığı, sonra ise kafasını yere çarptığı öğrenildi. Özgeçmişinde özellik yoktu. Acil servise 112 ekibi tarafından entübe olarak getirilen hasta aynı şekilde çocuk yoğun bakım ünitemize kabul edildi. Hasta servisimize geldiğinde genel durumu kötüydü, sedasyon altında ve entübe idi, ağrılı uyaranla göz açmaz ve motor yanıt vermez durumdaydı, ve bilateral ışı reaksiyonu pozitifti. GlasgowKoma skoru: 3 (E1V1M1) ve çocuk ölüm riski skoru 19 olarak değerlendirilen hastanın solunum, kardiyovasküler ve karın muayenelerinde patolojik özellik saptanmadı. Laboratuvar bulguları normaldi. Hastanın acil serviste çekilen beyin bilgisayarlı tomografisinde (BT) yaygın beyin ödemi ve lateral ventriküllerde, üçüncü ve dördüncü ventrikülde kanaması mevcut olup, basal sisternlerde, bilateral silvian sulkuslarda, anterior interhemisferik fissür ve prepontin sisternde SAK'ye rastlandı (Şekil 1). Servikal, batın ve pelvis BT'lerinde herhangi bir patolojik bulgu olmayan hastanın akciğer $\mathrm{BT}^{\prime}$ sinde her iki akciğer üst loblarda ve orta ve alt zonların posterior kesimlerinde akciğer kontüzyonu ile uyumlu yaygın buzlu cam görünümleri ve konsolidasyon alanları izlendi. Hastaya çekilen

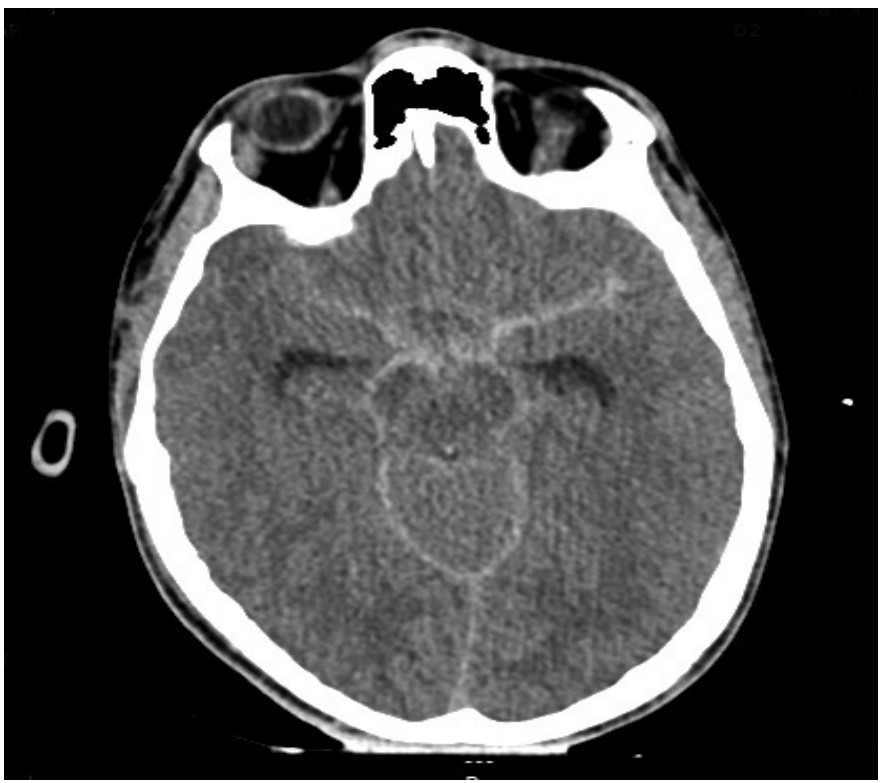

Şekil 1. Hastamızın beyin bilgisayarlı tomografi görüntülemesi beyin BT anjiyografinin normal olması nedeniyle beyin cerrahisi tarafından acil girişim düşünülmedi. Midazolam infüzyonu ile sedasyon, fentanil infüzyonu ile analjezi, rokuronyum infüzyonu ile nöromusküler blokaj sağlanan olgu basınç regüle hacim kontrol (PRVC) modda mekanik ventilatöre bağlandı (PEEP: $7 \mathrm{~cm} \mathrm{H} \mathrm{H}_{2}$, frekans: $15 \mathrm{sol} / \mathrm{dk}$, tidal hacim: $400 \mathrm{ml}$, $\mathrm{FiO}_{2}$ : \%70). Beyin ödemi tedavisi için \%3 hipertonik sodyum klorür $5 \mathrm{mgr} / \mathrm{kg}$ yükleme dozu sonrası $1 \mathrm{mgr} / \mathrm{kg} / \mathrm{sa}$ infüzyon şeklinde başlandı. Antiepileptik olarak levatirasetam, antibiyotik olarak seftriakson ve vankomisin tedavileri başlandı. Servisimizde bispektral indeks (BIS) ve near-infrared spectroscopy (NIRS) monitörizasyonları ile takip yapıldı. BIS düzeyinin 20-40 aralığında, NIRS düzeyinin 60-80 aralığında tutulması hedeflendi. Periferik oksijen satürasyonu $\left(\mathrm{SpO}_{2}\right)$ takibi yapılarak $\mathrm{FiO}_{2}$ kademeli olarak azaltıldı. Yatışının ikinci günü çekilen kontrol beyin $\mathrm{BT}^{\prime}$ de 3 , 4. ve lateral ventriküllerde kanama mevcut olup, hemisferik kortikal sulkuslar silik şeklinde yorumlandı, beyin cerrahisi tarafından tıbbi tedavinin devamı önerildi. Yatışııın dördüncü gününde çekilen kontrol beyin $\mathrm{BT}^{\prime}$ de kanamada azalma olması nedeniyle hastaya ekstübasyon planlandı. Beşinci gün sedasyonlar azaltılmaya başlandı, mekanik ventilatör modu önce senkronize aralıklı zorunlu ventilasyon (SIMV) PRVC'ye geçildi, sonrasında SIMV basınç kontrol basınç destek (PC + PS) olarak ayarlandı

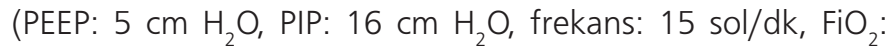
\%40). Hasta yatışının yedinci günü ekstübe edildi. Hasta kafa travması kabul edilip tüm takip ve tedavisi bu yönde yapılırken çocuk radyolojisi tarafından değerlendirilen görüntülemelerde bu bulguların altta yatan bir vasküler patolojiye sekonder olabileceği düşünüldü. Hasta yatışının sekizinci gününde girişimsel nöroradyoloji ile konsülte edilerek hızlıca serebral dijital subtraksiyon anjiyografisi (DSA) çekildi. Anjiyografi incelemesinde sağ PiCA proksimalinde yaklaşık üç milimetre çapında anevrizma odağı izlendi. Girişimsel nöroradyoloji tarafından aynı seansta sağ femoral arterden genel anestezi altında girilerek değişik boyut ve morfolojilerde koiller ile anevrizma kesesi tamamen doldurularak embolizasyon işlemi gerçekleştirildi (Şekil 2, 3). Ertesi gün çekilen beyin manyetik rezonans görüntülemede (MRG) her iki frontal lobda ve sağ temporooksipital bölgede kortikal ödem izlendi. Hastanın izlemi boyunca sodyum düzeyinin 150-155 mmol/L değerinde tutulması sağlandı. Fakat yatışının 10. gününden itibaren sodyum düzeylerinde düzensizlik saptanması ve $M R G^{\prime} d e$ kortikal ödem görülmesi nedeniyle hipertonik infüzyonu tedricen azaltılarak tedaviye mannitol eklendi. Beş gün boyunca mannitol ve kademeli azaltılan hipertonik infüzyonu tedavisi birlikte uygulanan hastanın çekilen kontrol beyin BT'sinde yeni kanama odağı, iskemi ve beyin ödemi saptanmaması üzerine mannitol tedavisi ve hipertonik tedavisi sonlandırıldı. Hasta yatışının 20. günü şifa ile taburcu edilerek çocuk nöroloji ve beyin cerrahisi poliklinik kontrolüne bağlandı. 


\section{Tartışma}

Çocukluk çağı İ'ları tesadüfen ortaya çıkabileceği gibi, baş ağrısı ve kitle etkisi gösterebilen semptomlarla da karşımıza gelebilir. Olguların \%20-80'inde ise ilk bulgu SAK olabilir. ${ }^{5}$ Şiddetli enfeksiyonlar, serebral veya servikal travmalar, doğuştan damar defektleri ve kalıtsal bağ dokusu hastalıkları yırtılmalarına zemin hazırlar., ${ }^{6,7}$ Hastamızın özgeçmişinde herhangi bir özellik olmaması ve ilk olarak anlatılan öyküsü, travmatik kanamayı düşündürmüş fakat görüntülemeleri tekrar

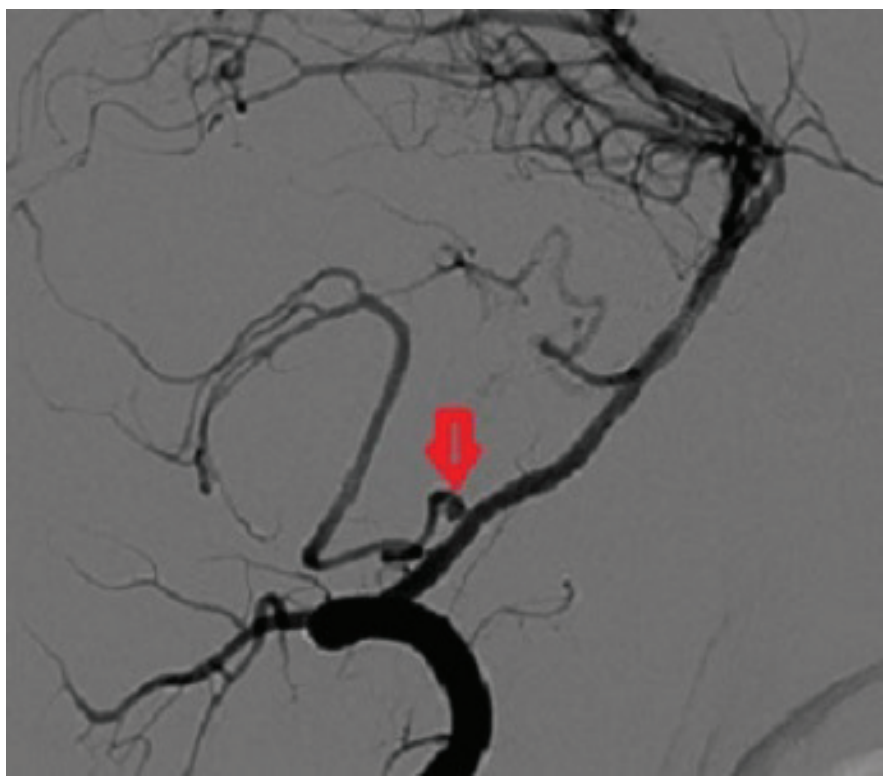

Şekil 2. Hastamızın dijital subtrakted anjiyografi görüntülemesi, ok işareti anevrizma kesesini göstermektedir

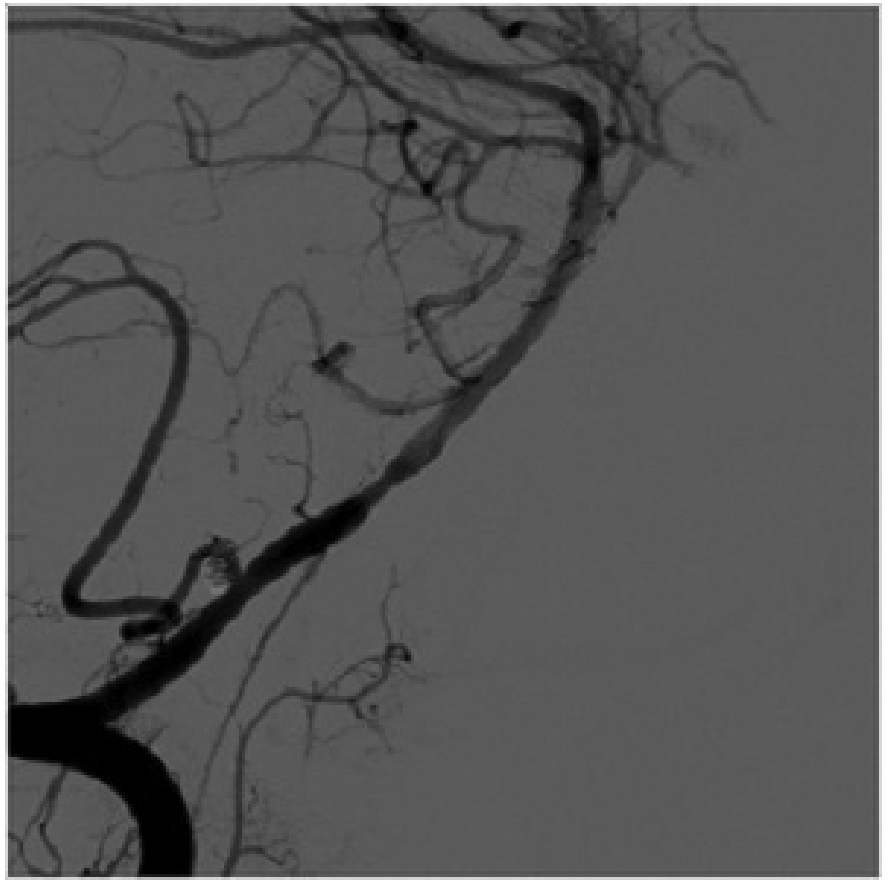

Şekil 3. Koilleme sonrası görüntü incelendiğinde bunun bir anevrizma kanaması olabileceği şüphesi uyandırmıştır. IA'ların görülme sıklığı çocuklarda erişkinlerden farklı olarak erkek cinsiyette daha baskındır. Aynı zamanda çocukluk yaş grubunda anevrizmaların bimodal yaş dağılımı vardır. Hastalar ilk 6 yaşta ve ergen dönemde bulguya yönelik hale gelmektedir. Özellikle anevrizmaların \%75'i 16 yaşından küçük erkek çocuklarda sıktır. ${ }^{8}$ Yerleşim yeri bakımından posterior sirkülasyon anevrizmaları çocuk yaş grubunda daha sık görülmektedir. ${ }^{9}$ Bizim hastamı da hem cinsiyet hem yaş hem de yerleşim yeri bakımından bu ölçütlere uymaktaydı.

Anevrizma tedavisinde cerrahi yöntemler ve endovasküler tedavi seçenekleri kullanılabilir. Endovasküler tedavide koil, stent yardımlı koil, balon yardımlı koil, akım yönlendirici stent ve akım bozucu cihazlar kullanılmaktadır. Tromboemboli, intraoperatif anevrizma rüptürü ve koil sarkmasına bağlı komplikasyonlar bu tedavi sırasında görülebilecek komplikasyonlardır. ${ }^{10}$ Literatürde çocukluk çağı IA'larının endovasküler tedavisinin cerrahi tedaviden daha düşük mortalite oranları ile ilişkili olduğunu gösteren çalışmalar mevcuttur. ${ }^{11}$ Sanai ve ark. ${ }^{12}$ iA tedavisi gören çocuklarda obliterasyon oranlarını endovasküler ve cerrahi grupta sırayla $\% 82$ ve \%94 olarak bildirmişlerdir. Endovasküler tedavi bu yönleriyle çocukluk çağı IA tedavisinde etkili olmakla birlikte \%15-20 oranında da nüks riski taşır. ${ }^{13}$ Hastamıza tanı konulan aynı seansta koilleme yöntemiyle endovasküler tedavi uygulanmış, tekrarlanan BT'sinde kanama olmaması nedeniyle tekrar bir girişim düşünülmemiştir.

Anevrizma büyüme oranlarının tutarsızlığı yüzünden çocukluk çağı iA'larını takip etmek için en uygun algoritma konusunda bir fikir birliği bulunmamaktadır. ${ }^{14}$ Ghali ve ark.'na ${ }^{5}$ göre endovasküler olarak tedavi edilen ve kompleks olmayan lezyonlar için, altıncı ayda anjiyografi kontrolü ve rekürrens yoksa, 12. ay ve iki ve beşinci yıllarda manyetik rezonans anjiyografi kontrolü önerilmektedir. ${ }^{15}$ Bizde hastamızın takibinde beyin cerrahisi, çocuk nöroloji ve girişimsel nöroradyoloji birimleri ile birlikte altıncı ay anjiyografi kontrolü planlayarak taburculuğu gerçekleştirdik.

Sonuç olarak, kafa travması ile gelen olgularda beyin BT görüntülemesinde genellikle epidural ya da subdural efüzyon/ hematom tarzı görüntüler beklenirken posterior ya da serebellar bölge gibi atipik yerleşimli kanamalarda özellikle SAK mevcudiyetinde bunun bir vasküler patolojiye bağlı olabileceği akla gelmeli ve hasta DSA için girişimsel radyoloji ile konsülte edilmelidir. Hızlı olarak yapılacak bir görüntüleme yöntemi ile aynı seansta gerçekleştirilebilecek bir tedavi yöntemi hastanın yaşam kalitesini artıralabilir.

\section{Etik}

Hasta Onayı: Hastadan makale yazımı için onam alınmıştır. 
Hakem Değerlendirmesi: Editörler kurulu dışında olan kişiler tarafından değerlendirilmiştir.

\section{Yazarlık Katkıları}

Konsept: H.S., Dizayn: M.T.P., Veri Toplama veya İsleme: N.A., Analiz veya Yorumlama: Ü.K.B., G.Ö., Literatür Arama: H.S.K., E.Ş., Yazan: Ü.K.B.

Çıkar Çatışması: Yazarlar tarafından çıkar çatışması bildirilmemiştir.

Finansal Destek: Yazarlar tarafından finansal destek almadıkları bildirilmiştir.

\section{Kaynaklar}

1. Steiner $T$, Juvela $S$, Unterberg $A$, Jung $C$, Forsting $M$, et al. European Stroke Organization guidelines for the management of intracranial aneurysms and subarachnoid haemorrhage. Cerebrovasc Dis. 2013;35:93-112.

2. Linn FH, Rinkel GJ, Algra A, van Gijn J. Incidence of subarachnoid hemorrhage: role of region, year, and rate of computed tomography: a meta-analysis. Stroke. 1996;27:625-9.

3. Locksley HB. Natural history of subarachnoid hemorrhage, intracranial aneurysms and arteriovenous malformations. Based on 6368 cases in the cooperative study. J Neurosurg. 1966;25:219-39.

4. Huang J, McGirt MJ, Gailloud P, Tamargo RJ. Intracranial aneurysms in the pediatric population: case series and literature review. Surg Neurol. 2005;63:424-32.

5. Ghali MGZ, Srinivasan VM, Cherian J, Kim L, Siddiqui A, et al. Pediatric Intracranial Aneurysms: Considerations and Recommendations for Follow-Up Imaging. World Neurosurg. 2018;109:418-31.
6. Winn RH. Youmans and Winnn eurological surgery. 7th ed. New York: Elsevier; 2017.

7. Leestma JE. Forensic neuropathology. 3rd ed. Boca Raton: CRC Press; 2014.

8. Krishna H, Wani AA, Behari S, Banerji D, Chhabra DK, et al. Intracranial aneurysms in patients 18 years of age or under, are they different from aneurysms in adult population? Acta Neurochir (Wien). 2005;147:469-76.

9. Aryan HE, Giannotta SL, Fukushima T, Park MS, Ozgur BM, et al. Aneurysms in children: review of 15 years experience. J Clin Neurosci. 2006;13:188-92.

10. Ulutabanca H, Kurtsoy A. Serebral Anevrizmalarda Endovasküler Tedavi: Akım Yönlendirici Stent ve Koil Kullanımı. Turk Nöroşir Derg. 2018;28:16-21.

11. Alawi A, Edgell RC, Elbabaa SK, Callison RC, Khalili YA, et al. Treatment of cerebral aneurysms in children: analysis of the Kids' Inpatient Database. J Neurosurg Pediatr. 2014;14:23-30.

12. Sanai N, Quinones-Hinojosa A, Gupta NM, Perry $V$, Sun PP, et al. Pediatric intracranial aneurysms: durability of treatment following microsurgical and endovascular management. I Neurosurg. 2006;104(2 Suppl):82-9.

13. Gemmete JJ, Toma AK, Davagnanam I, Robertson F, Brew S. Pediatric cerebral aneurysms. Neuroimaging Clin N Am. 2013;23:771-9.

14. Hetts SW, English JD, Dowd CF, Higashida RT, Scanlon JT, et al. Pediatric intracranial aneurysms: new and enlarging aneurysms after index aneurysm treatment or observation. AJNR Am J Neuroradiol. 2011;32:2017-22.

15. Broderick JP, Brott TG, Duldner JE, Tomsick T, Leach A. Initial and recurrent bleeding are the major causes of death following subarachnoid hemorrhage. Stroke. 1994;25:1342-7. 